\title{
Optimization of Arranging of Repair Works at Oil and Gas Enterprises through Use of Simulation Modeling Tools
}

\author{
Iryna Hobyr * \\ Department of Applied Economics \\ Ivano-Frankivsk National Technical \\ University of Oil and Gas \\ Ivano-Frankivsk, Ukraine \\ http://orcid.org/0000-0002-9322-8404
}

\author{
Vitalina Babenko \\ International E-commerce and \\ Hotel \&Restaurant Business \\ Department \\ V. N. Karazin Kharkiv National \\ University \\ Kharkiv, Ukraine \\ http://orcid.org/0000-0002-4816-4579 \\ Juliia Bui \\ Department of Applied Economics \\ Ivano-Frankivsk National Technical \\ University of Oil and Gas \\ Ivano-Frankivsk, Ukraine \\ http://orcid.org/0000-0003-0096-2384
}

\author{
Oksana Savko \\ Department of Applied Economics \\ Ivano-Frankivsk National Technical \\ University of Oil and Gas \\ Ivano-Frankivsk, Ukraine \\ http://orcid.org/0000-0002-7282-7731
}

\begin{abstract}
There is substantiated the expediency of using the methods of the queuing theory for making managerial decisions in the face of uncertainty and risk. The model of organizing repair works at oil and gas companies has been improved, and its implementation ensures the optimization of the costs of maintaining repair crews and the reduction of losses from well downtime. Well repair by repair crews is considered as a multichannel queuing system in which the flow of service requests is the flow of repair applications, and the maintenance procedure consists of providing a repair crew according to applications in the order they are received. The maintenance procedure consists in the use of a repair crew according to the application, which is considered completed after the completion of the work of this crew at the facility, and the order of satisfying applications is carried out in the order they are received. Testing the proposed model of organizing repair works on the example of the fields of the three largest oil and gas companies in the Western region of Ukraine made it possible to establish that an increase in the failure rate requires an increase in the number of repair crews. However, such an increase is not always advisable, since the costs of maintaining the crews begin to exceed the losses from the downtime of the wells. The problem has been solved by the simulation method to optimize the elimination of failures of tubing (breaks) in the fields of the studied oil and gas producing enterprises, the process of which includes operations associated with the formation, transformation and implementation of random events, variables and processes that cause random changes in the state of such a system.
\end{abstract}

Keywords-expenses, oil and gas companies, queuing theory, repair crews, repairs, simulation, wells

\section{INTRODUCTION}

The strategic importance of oil and gas production facilities necessitates choosing the optimal development strategy for such facilities, which is determined by the indicators of economic efficiency and development of enterprises. Also, competition and deregulation of market require lowering the costs of enterprises as a necessary condition for their survival. In this regard, the importance of the effective organization and management of the repair services of oil and gas companies is significantly increasing.

The rational organization of maintenance and repair is an important factor in improving the use of equipment, improving the quality and reducing the cost of oil and gas, which generally contributes to the sustainable development of enterprises. Therefore, the problem of an objective assessment of the effectiveness of repair services arises, which can be done by comparing the effect obtained and the cost of achieving it. The basis for determining the beneficial effect as a result of the repair service of the enterprise is a direct relationship between the volume of hydrocarbon production and the intensity of use of equipment. That is, as a result of the effective operation of the equipment (due to the high level of organization and management of repair works), the volume of oil and gas production increases and, as a result, the profit of the enterprise grows.

\section{THE TASK OF MASS SER VICE FOR THE ORGANIZATION AND MANAGEMENT OF REPAIR SERVICES OF OIL AND GAS \\ COMPANIES}

Oil and gas production enterprises of Ukraine have an extensive organizational structure and a complex technological and production process, which is characterized by significant risks to their activities [1].

In conditions of uncertainty, when making managerial decisions, the queuing theory is widely used: to ensure undisturbed operation of equipment at enterprises [2], increasing the efficiency of the enterprise [3], supporting various business processes at the enterprise [4].

Since an insufficient number of repair crews at oil and gas production enterprises or untimely maintenance can lead to well downtime and significant damage, therefore well repair by crews can be considered as a multi-channel queuing system with applications for repairs as a stream of 
service requirements. The maintenance procedure consists in the allocation of a repair crew according to the application. The application is considered to be satisfied after the completion of the work of the crew at the facility. There is a queue of applications to be satisfied in the order they are received. The application, which is received when all the repair crews are busy, remains in the system until it is satisfied.

When setting the queuing problem for the organization and management of repair services of oil and gas companies, it is assumed that the system has $\mathrm{N}$ repair teams (absolutely reliable service channels). Demand for repair crews is characterized by the flow of applications from individual wells requiring the $j^{\text {th }}$ type of work. The intensity of the flow of applications for the repair team from the $i^{t h}$ well, requires the $j^{\text {th }}$ type of work (the average number of applications per unit time), is $\lambda_{i j}$. The duration of the work by the repair team at the $i^{\text {th }}$ well, which requires the $j^{\text {th }}$ type of work, is $t_{i j}$ days. It is assumed that $t_{i j}$ is a random variable having one or another distribution law. It is also necessary to enter a value $\mu=1 / T_{i j}$ - the intensity of servicing applications, where $T_{i j}$ is the average duration of the crew`s work at the facility.

The condition for the existence of a stationary mode of operation of the queuing system (when the queue of service applications is stabilized) is the inequality as follows.

$$
N>\rho=\lambda / \mu
$$

where $\lambda=\frac{b}{a}\left(\frac{t}{a}\right)^{b-1}-$ is the rate of unprocessed applications.

The parameter $\rho$, which is called the loading of the service channel, plays a pivotal role in any characteristics of the system: the greater is the load and the closer is the performance boundary, the longer is the average time of requirements in the system, that is, there are more downtimes of wells.

The objective function in solving the problem of substantiating the need for repair crews is the average amount of expenses for their maintenance and losses from downtime of wells:

$$
C_{\Sigma_{i}}=\left(C_{i}^{\text {const }} N_{i}+C_{i}^{\mathrm{var}} \bar{N}_{i}\right)+\sum_{j=1}^{n} Q_{j} \bar{M}_{j}, i=\overline{1, m}
$$

where $C_{i}^{\text {const }}$ are fixed costs of an hour work of the $i^{\text {th }}$ crew;

$N_{i}$ is the number of $i$ repair crews;

$C_{i}^{\mathrm{var}}$ are semi-variable costs of an hour work of the $i^{\text {th }}$ crew;

$\bar{N}_{i}$ is the average number of working $i$ teams, equal to $\rho$;

$Q_{j}$ are hourly average losses from downtime of the $j^{\text {th }}$
$M_{j}$ is the average number of $j^{\text {th }}$ idle wells.

We assume that the sequence of moments of applications receipt for repair crews is a Poisson stream, and the duration of their work during well repairs is distributed exponentially. If condition (2) is satisfied, then the average number of idle wells is as follows

$$
\bar{M}_{j}=\frac{\rho^{N_{i}+1}}{\left(N_{i}-1\right) !\left(N_{i}-\rho\right)^{2}} p_{0}
$$

The value $p_{0}$ is the probability of simultaneous downtime of all wells, which is determined by the formula:

$$
p_{0}=\frac{1}{\sum_{k=0}^{N_{i}-1} \frac{\rho^{k}}{k !}+\frac{\rho^{N_{i}}}{N_{i} !\left(1-\rho / N_{i}\right)}}
$$

In fact, the flow of applications is not always subject to Poisson distribution law, or there are no assumptions regarding the law of distribution. In this case, simulation can be applied for the rational management.

\section{SOLVING THE PROBLEM OF OPTIMIZING THE REPAIR WORKS USING SIMULATION}

Simulation is a computational procedure that does not require to bring the model to a specific form $[5,6,7]$. It allows us to simulate the operation of systems with different distribution laws, modes and in various industries $[8,9,10]$.

This approach has considerable flexibility, and the model obtained as a result of a simulation experiment can be brought into line with the system under study $[11,12,13]$.

The simulation process includes a significant number of operations related to the formation, transformation and description of the occurrence of random events, random variables and random processes that accompany random changes in the states of the system. Therefore, the trajectories of the motion of a complex system in the set of its states, which are obtained by imitation, are random functions of time. The source material for making any random objects is the so-called random numbers specified by the random number sensor. Random numbers can be considered as possible values $x_{i}$ of a random variable $\xi$, approximately described by the normal distribution law in the interval $(0 ; 1)$. The methods of constructing various complex random objects from random numbers have been sufficiently developed at present and are called the conversion of random numbers.

If there are no free repair crews in the system to meet the next application, a downtime of the $i^{\text {th }}$ well arises, and it requires the completion of the $j$ type of work, the duration of which is $\tau_{i j}$ in days and depends on the moment the repair crew is free having fulfilled a previous task (application).

The objective function of the mathematical model of the process of providing wells with repair crews is as follows well; 


$$
C_{\Sigma}=C_{a} N+\sum_{t=0}^{T_{c}} \sum_{j=1}^{n} \sum_{i=1}^{m} C_{i j} \tau_{i j} \rightarrow \min
$$

where $C_{a}$ are average annual maintenance costs for crews;

$C_{i j}$ are the average daily losses from the downtime of the $i^{\text {th }}$ well that requires the completion of the $j^{\text {th }}$ type of work;

$T_{c}$ is the moment of the process stabilization.

In case of simulation, the state of the system at the next moment in time depends on its state at the previous moment. At the beginning of the simulation, it is necessary to set the initial state of the system, which is unknown. If we accept that all the repair crews are free at the initial moment, then it takes some time to get an objective picture of the use of the crews. We call it the duration of the process stabilization and assume that the process has reached stabilization if the relative downtimes of the crews have stabilized, that is, the following condition is fulfilled

$$
0<\Delta \tau\left(T_{c}\right)-\Delta \tau\left(T_{c-1}\right)<\varepsilon
$$

where $\Delta \tau\left(T_{c}\right)$ is an accumulated relative duration of downtime by the crews at the moment $T_{c}$ :

$$
\Delta \tau\left(T_{c}\right)=\frac{\sum_{t=0}^{T_{c}} \sum_{j=1}^{n} \sum_{i=1}^{m} \pi i j}{T_{c}}
$$

where $\varepsilon$ is the predetermined value.

The value $\varepsilon$ determines the accuracy of calculations in the simulation process. The reduction in formula (6) is the relative downtime of the crews at the moment of the process stabilization, and the denominator is the same at the previous moment of time. The difference must be non-zero, otherwise, due to the fact that all crews are free and the downtimes are equal to zero level at the beginning of the simulation, it will end without starting.

Due to the fact that the cost of maintaining repair crews is calculated on an annual average, the simulation should last until the time equal to one year. An additional condition is therefore required

$$
T_{c}<T_{r}
$$

where $T_{r}$ is one year in units of measurement of time modeling.

If condition (8) is not fulfilled, the simulation should be extended to two, three years and, if necessary, further, which should be taken into account when determining the scale of maintenance costs for repair crews.

Expressions (1)-(8) constitute a mathematical model of the well service process, where expression (5) is a goal function and others are constraints.

To solve the problem, we need the following data:

- a list of wells that should be serviced by repair crews;
- $\quad$ types and parameters of laws for the distribution of applications for crews and the duration of repair works for each well;

- $\quad$ losses from well downtime per unit of time;

- average annual maintenance costs for one crew;

- the number of repair crews (the minimum number of crews is determined on the basis of condition (1) an then increases by one at each calculation cycle until the value of the objective function (5) begins to decrease);

- the value $\varepsilon$, the moment of completion of calculations.

\section{ALGORITHM FOR MODELING REPAIR WORK IN WELLS}

In Figure 1 block 1 simulates the time of the next application for the crew of the $j^{\text {th }}$ well. For this, the random number sensor provides a random number, which is uniformly distributed in the interval $[0,1]$.

Depending on the parameters of the selected law for the distribution of applications for repair crews according to a special program, this random number turns into a random number corresponding to a given distribution law.

Unit 2 chooses the moment of the earliest application. This moment is at the same time the next moment of modeling, that is, the program "goes" at this moment into the real timescale.

The logical operator determines the availability of free crews. If there is a free crew, it is allocated to satisfy the application in question. The application is considered to be satisfied, and the repair team - busy with repair works until the end of work at the facility, which is modeled by unit 3 .

Unit 3 functions similarly to unit 1 , but converts a uniformly distributed random number in accordance with the distribution law of the duration of the repair crew work on the $\mathrm{j}^{\text {th }}$ well. Information on the work of the repair crew is transmitted to unit 4, just like the information being produced by unit 5 .

Unit 6 determines the utilization rate of the repair crew in time as the ratio of the number of busy crews to the total number of repair crews $N$ to determine the moment of the process stabilization under the condition similar to condition (6).

When the logical unit determines the absence of crews during the next application for the repair work, the unit 7 comes into operation, which determines the downtime of the well as the difference between the earliest time the crew is free and the moment the application arrived.

Unit 8 calculates the relative duration of well downtime, and the logical unit determines whether stabilization of the process has been achieved under conditions (6) and (8). If the answer to this question is negative, the modeling procedure continues; if the answer is positive, block 9 calculates the total costs for maintaining the crews, losses from well downtime and determines the value of the objective function by summing the cost components (5).

The components of cost and the value of the objective function (5) are printed, after that adjustments are made to the initial data, and the specified number of crews is increased by one. This continues until the value of the objective function decreases. Its increase indicates that the optimal number of repair crews is obtained at the previous stage of modeling.

An exhaustive characteristic of the reliability of oilfield 
equipment is the law of distribution of time between failure. If the form of this law and its parameters are known, then it is relatively easy to determine any characteristic of the operational reliability of the system. A statistical definition of the law of uptime is associated with significant difficulties.

To set it, according to the statistical data, graphs of statistical functions of the reliability indicator are built.

Since the density of distribution more clearly reflects the specific features of the distribution law, then, as a rule, this function is first built so that one could assume the form of the distribution law according to its form.

When constructing the statistical function of the distribution density along the abscissa, the intervals of the statistical series are laid aside. At each interval of the statistical series there is a rectangle, the height of which is equal to the ratio of the frequency to the width of the interval.

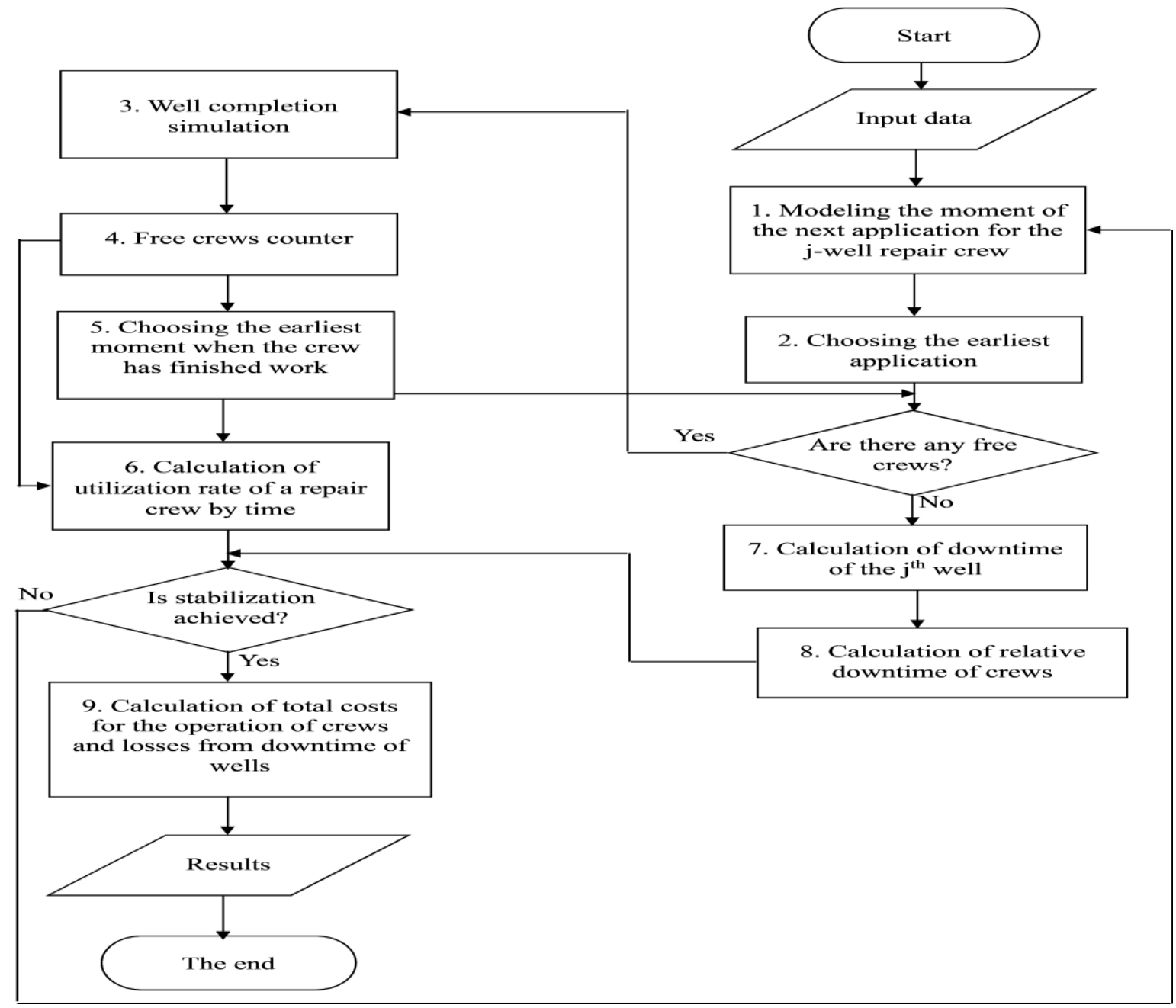

Fig. 1. A simulation model of the organization of repair works in wells

When processing statistical material, an important task is the selection of the theoretical distribution law, which expresses its essential properties without an element of randomness.

The theoretical law is chosen, taking also into account:

- the physical nature of failures;

- the shape of the distribution density curve;

- the coefficient of variation.

The value of the coefficient of variation is determined by the formula

$$
V=\frac{\sigma}{\bar{t}}
$$

where $\sigma$ is the standard deviation; $\bar{t}$ is the average value of the system uptime, allowing to judge the operating conditions of oilfield equipment.

It is known that if a coefficient of variation is $V<0.3$, a normal distribution takes place, and if $V>0.5$, there is a Weibull distribution. The Weibull distribution function has the following form

$$
F(t)=1-\exp \left[-(t / a)^{b}\right]
$$

where $a$ i $b$ are Weibull distribution parameters

The parameter $b$ can be determined through the coefficient of variation. The parameter $a$ is calculated from the expression $a=\bar{t} / K_{b}$ or $a=\sigma / C_{b}$, where $K_{b}$ and $C_{b}$ are the coefficients determined with the known coefficient of variation. When $b=1$, the Weibull distribution 
transforms to the exponential, and when $b=2,5 \div 3,5$ it is close to the normal one. Therefore, the Weibull distribution is considered as a very flexible law and is widely used in reliability theory. Obviously, the Weibull distribution takes place for equipment failures resulting from its wear and aging, as well as for device failures consisting of seriesconnected elements.

\section{APPLICATION OF MODELS OF ORGANIZATION OF REPAIR WORK}

Practical application of the proposed models of the organization of repair works has been carried out on the example of the fields of the largest oil and gas production enterprises (OGPE) of the public joint-stock company

Ukrnafta - OGPE Boryslavnaftogaz, OGPE Dolynanaftogaz and OGPE Nadvirna Naftogaz. Based on the results of processing the field data, there were established the laws for the distribution of failures of oilfield equipment in the fields, described by the Weibull distribution.

So, breaks in tubing in oil and gas fields obey the law of probability of failure-free operation, which is described by the expression

$$
P(t)=\exp \left[-\left(\frac{t}{496}\right)^{1,8}\right]
$$

The following parameter values are accepted for calculations:

$T_{i j}=24$ days - the average duration of a repair crew use at the facility;

$C_{i}^{\text {const }}=51,5$ conventional units - fixed costs in the cost of an hour work by the crew;

$C_{i}^{\mathrm{var}}=49,5$ conventional units - conditionally variable costs in the cost of an hour work by the crew;

$Q_{j}=620,3$ conventional units - hourly average losses from idle j-well.

Based on the distribution of the probability of failurefree operation established by law, there are calculated the optimal between-repairs period and failure rates. The calculation results are summarized in Table I.

Table II presents the results of the calculation of costs depending on the number of crews at a failure rate $\lambda=0,001935$

TABLE I. OPTIMUM BETWEEN-REPAIRS PERIODS AND FAILURE RATES

\begin{tabular}{|c|c|}
\hline Optimal between-repairs period, days & Failure rates of the well, $\boldsymbol{\lambda}$ \\
\hline 226 & 0,001935 \\
\hline 254 & 0,002125 \\
\hline 308 & 0,002479 \\
\hline
\end{tabular}

TABLE II. TOTAL COSTS FOR WELL MAINTENANCE PROCESSES AT FAILURE RATE $\lambda=0,001935$

\begin{tabular}{|c|c|c|c|c|c|c|}
\hline The number of repair crews & 7 & 8 & 9 & 10 & 11 & 12 \\
\hline Losses from downtime, conventional units & 8301,47 & 1481,36 & 506,09 & 197,19 & 79,65 & 32,06 \\
\hline $\begin{array}{l}\text { The cost of maintaining repair crews, } \\
\text { conventional units }\end{array}$ & 675,11 & 725,63 & 777,11 & 827,62 & 878,13 & 929,62 \\
\hline Total cost, conventional units & 9002,81 & 2233,22 & 1308,46 & 1051,04 & 984,01 & 987,90 \\
\hline
\end{tabular}

With an increase in the number of crews from 7 to 11 , a sharp (9 crews) decrease in total costs occurs first. The involvement of the 12th crew becomes impractical, since the total costs increase due to the additional costs of maintaining the crews. The total costs include the costs of maintaining crews and oil losses during wells downtime, that is, they can be adjusted due to one or another component.
When analyzing the dependencies (Table III), a similar trend is observed for the dependencies presented in Table II. That is, the optimal number of repair crews is 12 . The involvement of another crew is unprofitable. Although losses from downtime continue to decline, at the same time, costs for crews are growing, which, in turn, increases total costs by $2.8 \%$.

TABLE III. TOTAL COSTS OF WELL SERVICING PROCESSES AT FAILURE RATE $\lambda=0,002125$

\begin{tabular}{|l|c|c|c|c|c|c|c|}
\hline \multicolumn{1}{|c|}{ The number of repair crews } & $\mathbf{7}$ & $\mathbf{8}$ & $\mathbf{9}$ & $\mathbf{1 0}$ & $\mathbf{1 1}$ & $\mathbf{1 2}$ & $\mathbf{1 3}$ \\
\hline $\begin{array}{l}\text { Losses from downtime, } \\
\text { conventional units }\end{array}$ & 13555,7 & 1804,84 & 597,4 & 233,13 & 94,22 & 38,86 & 15,54 \\
\hline $\begin{array}{l}\text { The cost of maintaining repair } \\
\text { crews, conventional units }\end{array}$ & 701,34 & 751,85 & 803,34 & 853,85 & 904,36 & 955,84 & 1006,36 \\
\hline Total cost, conventional units & 14256,07 & 2556,69 & 1399,77 & 1086,01 & 999,56 & 993,73 & 1021,9 \\
\hline
\end{tabular}

Table IV shows the results of cost calculation depending on the number of crews with the failure rate $\lambda=0,002479$.
With the failure rate $\lambda=0,002479$, the optimal number of crews is 13 , so that total costs decrease by $0.8 \%$ due to a decrease in loss from downtime by $57.9 \%$.

TABLE IV. TOTAL COSTS OF WELL SERVICING PROCESSES AT FAILURE RATE $\lambda=0,002479$

\begin{tabular}{|c|c|c|c|c|c|c|c|}
\hline The number of repair crews & 8 & 9 & 10 & 11 & 12 & 13 & 14 \\
\hline Losses from downtime, conventional units & 8351,01 & 1664,96 & 597,40 & 243,82 & 103,94 & 43,71 & 18,46 \\
\hline $\begin{array}{l}\text { The cost of maintaining repair crews, } \\
\text { conventional units }\end{array}$ & 801,39 & 851,91 & 902,42 & 953,90 & 1004,41 & 1055,90 & 1106,41 \\
\hline Total cost, conventional units & 9152,41 & 2516,86 & 1499,82 & 1197,72 & 1107,38 & 1098,64 & 1123,89 \\
\hline
\end{tabular}




\section{DETERMINING THE OPTIMAL NUMBER OF CREWS FOR VARIOUS FAILURE RATES}

If the failure rate is $\lambda=0,001935$, the optimal number of crews is 11 , the total costs are 984.01 conventional units, if $\lambda=0,002125$ - respectively 12 and 993.73 conventional units, if $\lambda=0,002479$ - respectively 13 and 1098.64 conventional units. A further increase in the number of repair crews is inefficient, although losses from well downtime are reduced, but the costs of their maintaining are growing much faster, which leads to an increase in total costs. With an increase in the number of crews, losses from well downtime are rapidly decreasing, then gradually equalizing. This is due to the fact that at first the losses from downtime are very high, and the costs of maintaining the crews are relatively low.

Table $\mathrm{V}$ show that losses from downtime of wells at different $\lambda$, when 8 and 9 crews work, are significantly different. In the future, the situation is leveled. This is due to the fact that a larger number of crews repair more wells, reducing their downtime, but at the same time, their maintenance costs increase.

TABLE V. LOSSES FROM DOWNTIME OF WELLS AT DIFFERENT $\lambda$

\begin{tabular}{|l|c|c|c|c|c|c|c|c|}
\hline The number of repair crews & $\mathbf{7}$ & $\mathbf{8}$ & $\mathbf{9}$ & $\mathbf{1 0}$ & $\mathbf{1 1}$ & $\mathbf{1 2}$ & $\mathbf{1 3}$ & $\mathbf{1 4}$ \\
\hline$\lambda=\mathbf{0 , 0 0 1 9 3 5}$ & 8301,47 & 1481,36 & 506,09 & 197,19 & 79,65 & 32,06 & - & - \\
\hline$\lambda=\mathbf{0 , 0 0 2 1 2 5}$ & 13555,7 & 1804,84 & 597,40 & 233,13 & 94,22 & 38,86 & 15,54 & - \\
\hline$\lambda=\mathbf{0 , 0 0 2 4 7 9}$ & - & 8351,01 & 1664,96 & 597,40 & 243,82 & 103,94 & 43,71 & 18,46 \\
\hline
\end{tabular}

Table VI shows that the minimum total costs are in the range from 1013 conventional units up to 1131 conventional units that is, the number of crews varies from 11 to 13 .
With the increase in the failure rate, the cost curves shift to the right, which is explained by a large number of repairs, and as a result, there is required an additional number of repair crews

TABLE VI. THE TOTAL COSTS OF WELL SERVICING PROCESSES FOR VARIOUS $\lambda$

\begin{tabular}{|l|c|c|c|c|c|c|c|c|}
\hline The number of repair crews & $\mathbf{7}$ & $\mathbf{8}$ & $\mathbf{9}$ & $\mathbf{1 0}$ & $\mathbf{1 1}$ & $\mathbf{1 2}$ & $\mathbf{1 3}$ & $\mathbf{1 4}$ \\
\hline $\boldsymbol{\lambda}=\mathbf{0 , 0 0 1 9 3 5}$ & 9002,81 & 2233,22 & 1308,46 & 1051,04 & 984,01 & 987,90 & - \\
\hline$\lambda=\mathbf{0 , 0 0 2 1 2 5}$ & 14256,1 & 2556,69 & 1399,77 & 1086,01 & 999,56 & 993,73 & 1021,90 & - \\
\hline$\lambda=\mathbf{0 , 0 0 2 4 7 9}$ & - & 9152,41 & 2516,86 & 1499,82 & 1197,72 & 1107,38 & 1098,64 & 1123,89 \\
\hline
\end{tabular}

\section{CONCLUSION}

The solution by the simulation method to optimize the elimination of failures of tubing (breaks) in the fields of the studied oil and gas enterprises, the process of which includes a huge number of operations associated with the formation, transformation and implementation of random events, quantities and processes that cause random changes in the state of such a system confirms the results obtained above.

The simulation toolkit proposed and adapted to the operating conditions of repair crews at oil and gas producing enterprises allows optimizing the costs of maintaining crews while minimizing losses from well downtime.

\section{REFERENCES}

[1] I. Khvostina, N. Havadzyn and N. Yurchenko, "Manifestation of the emergent properties in risk assessment of oil and gas companies", The 8th Intern. Conf. on Monitoring, Modeling \& Management of Emergent Economy(M3E2 2019),, vol. 65, Odessa, Ukraine, May 2019, pp.157-168. [Online]. Available: https://www.shsconferences.org/articles/shsconf/abs/2019/06/contents/contents.html. doi: 10.1051/shsconf/20196508001.

[2] P. G. Pererva, and I. N. Pogorelov, "The study of queuing systems to ensure the smooth operation of equipment in enterprises", Bulletin of the National Technological University “KhPI”, vol. 8, pp.187-191, 2011. [in Ukrainian].

[3] O. Lytvynova, "Using queuing systems for the increase of enterprise efficiency", Economy. Management. Innovation, vol. 2 (17), 2016. [Online]. Available:http//nbuv.gov.ua/UJRN/eui_2016_2_13. [in Ukrainian].

[4] I. G. Haugg, R. Z. Frantz, F. Roos-Frantz, S. Sawickie, and B. Zucolotto, "Towards optimisation of the number of threads in the integration platform engines using simulation models based on queueing theory", Revista Brasileira de Computação Aplicada, vol. 11, no 1, pp. 48-58, April, 2019.

[5] E. V. Danilets, G. A. Raiko, and G. A. Ignatenko, "Using simulation to analyze enterprise management systems", Visnyk of Kherson National Technical University, no 4 (43), pp. 157-161, 2011. [in Russian].

[6] O. Piddubna, and O. Litvinova, "Methods of simulation in the analysis of the economic systems", Investment: Practice and Experience, vol. 24, pp. 65-69, 2013. [in Ukrainian].

[7] R. Shamrin, "Simulation modeling of economic systems: software tools and areas of improvement", Economy and State, vol.1, pp 35-39, 2016. [in Ukrainian].

[8] A. S. Makova, "Prospects for the development of simulation modeling", Modern High Tecnology, no 7-1, pp. 59-60, 2014. [in Russian].

[9] O. Lytvynova, "Methods of simulation of reliability's assessing of the elementary systems", Reporter of the Priazovskyi State Technical University, vol. 1, pp. 168-175, 2016. [in Ukrainian].

[10] P. V. Skorodumov, "Simulation modelling of economic systems:software tools and areas of improvement", Problems of Territory's Development, vol. 2 (76), pp.62-72, 2015. [in Russian].

[11] N. Lychkina, "Dynamic simulation of socio-economic systems and its application in information-analytical solutions for strategic management", Business Strategies, vol. 2, pp. 44-49, 2013. [in Russian].

[12] T. Barkalova, T. Kokotkina, and E. Tsaregorodtsev "Challenges and Opportunities of Using Simulation Models in Forecasting Socioeconomic Development of the Region", International journal of environmental \& science education, vol. 11, no. 17, pp.10661-10671, 2016.

[13] A. M. Korovin, "The analysis of approaches and software for the simulation of social and economic systems", Vestnik of SUSU, vol.35, pp. 98-100, 2012. [in Russian]. 